\title{
Timing of ovulation after gonadotrophin induction and its importance to successful intrauterine insemination in the tiger (Panthera tigris)
}

\author{
A. M. Donoghue ${ }^{1,2}$, A. P. Byers ${ }^{1,3}$, L. A. Johnston ${ }^{4}$, D. L. Armstrong ${ }^{4}$ \\ and D. E. Wildt ${ }^{1,3}$ \\ ${ }^{1}$ Department of Reproductive Physiology, Conservation and Research Center, National Zoological Park, \\ Smithsonian Institution, Front Royal, VA 22630, USA ${ }^{2}$ Germplasm and Gamete Physiology Laboratory, \\ ARS, USDA Beltsville, MD 20705, USA; ${ }^{3}$ Conservation Breeding Specialist Group, Apple Valley, \\ MN 55124, USA; and ${ }^{4}$ Henry Doorly Zoo, Omaha, NE 68107, USA
}

The ovarian response to equine chorionic gonadotrophin (eCG) and human chorionic gonadotrophin (hCG), the effect of timing of ovulation relative to hCG injection and the use of laparoscopic intrauterine artificial insemination (AI) were examined in two subspecies of tiger (Panthera tigris). Adult female tigers were subjected to the same eCG/hCG treatment followed by laparoscopy under xylazine/diazapam/ketamine $\mathrm{HCl}$ anaesthesia at 39-42 $\mathrm{h}$ (Group I, $n=9$ ), 46-49 h (Group II, $n=5$ ) or 51-55 h (Group III, $n=5$ ) after hCG. Six of these females, observed to be postovulatory at the time of laparoscopy (Group II, $n=3$; Group III, $n=3$ ), were subjected to intrauterine AI. The number of preovulatory follicles observed on the ovaries of Group I females was twofold greater $(P<0.05)$ than the number observed on ovaries of females in Group II and III. Fewer $(P<0.05)$ corpora lutea were observed on ovaries of Group I females ( $1.3 \pm 0.6)$ compared with the number of corpora lutea in Group II and III (combined average, $7.8 \pm 0.8$ corpora lutea per female). Only one of ten females in Groups II and III failed to ovulate by the time of laparoscopy. Four Group I females never ovulated, based on a laparoscopic re-evaluation 4 weeks later. One female inseminated $46 \mathrm{~h}$ after hCG (Group II) became pregnant and delivered a healthy cub after a normal gestation. There were no apparent differences between subspecies in response to the same ovulation induction protocol. Results demonstrate the importance of the relationship between exogenous gonadotrophin treatment and onset of anaesthesia for laparoscopic examination and AI in tigers. Data clearly indicate that anaesthesia/laparoscopy conducted too early (39-42 h after hCG) compromises the number of females and proportion of follicles ovulating. In contrast, ovulation success is high if anaesthesial laparoscopy is performed after this time, and intrauterine insemination can result in healthy young.

\section{Introduction}

The tiger Global Animal Survival Plan (GASP) is a strategy developed by the IUCN/Species Survival Commission's Conservation Breeding Specialist Group for the integrated management of tigers internationally (Tilson $e t$ al., 1993). The plan links in situ and ex situ conservation for the recovery and long-term maintenance of captive and wild populations of tigers. One priority of the tiger GASP is to develop assisted reproductive techniques including artificial insemination (AI), in vitro fertilization/embryo transfer (IVF/ET) and a genome resource bank (an organized frozen repository of germplasm, blood products, tissue and DNA). Live-born offspring have been produced after AI (Donoghue et al., 1993) and IVF/ET (Donoghue et al., 1990) in tigers, and embryos have

Received 27 November 1995. been produced in vitro using frozen-thawed spermatozoa (Donoghue et al., 1992a). Nonetheless, the ultimate utility of assisted reproductive technology will depend upon its consistent usefulness in routinely generating offspring from genetically selected parents.

Artificial insemination has long been an effective tool for domestic animal reproduction (Faulkner and Pineda, 1980). Although this technology has obvious benefits for nondomestic species (overcoming behavioural incompatibility between pairs, moving germplasm rather than stress susceptible wild animals, and using cryopreserved spermatozoa to assist preserving and distributing genetic diversity), before the 1990 s there was only one published report concerning the birth of live-born felid offspring (puma, Felis concolor) after AI (Moore et al., 1981). More recently, an intrauterine AI technique has been used to produce live-born young in domestic cats (Felis catus; Howard et al., 1992a), leopard cats (Felis 
bengalensis; Wildt et al., 1992), pumas (Barone et al., 1994), clouded leopards (Neofelis nebulosa; Howard et al., 1996), cheetahs (Acinonyx jubatus; Howard et al., 1992b), ocelots (Felis pardalis; Swanson et al., 1995) and snow leopards (Panthera unica; T. L. Roth and D. E. Wildt, unpublished). An important component to these successes was an earlier observation that anaesthesia (required for laparoscopic $\mathrm{AI}$ ) can inhibit ovulation (Howard et al., 1992a). Specifically, when domestic cats are anaesthetized with ketamine hydrochloride, acepromazine and gaseous halothane before ovulation, few females ovulate and the pregnancy rate is low (14\%). Conversely, if the interval from administration of hCG to anaesthesia is increased (to 6-14 h after ovulation has begun), 100\% of cats ovulate and approximately half of these become pregnant and deliver live offspring (Howard et al., 1992a).

As part of a long-term programme to study the basic biology and to adapt assisted reproductive technology to tigers, the objectives of this study were to determine the relative timing of ovulation in tigers after exogenous gonadotrophin treatment and to evaluate whether the timing of laparoscopy or anaesthesia may potentially inhibit ovulation. Because two tiger subspecies were available, we also had the opportunity to evaluate the influence of subspecies on the success of ovulation induction.

\section{Materials and Methods}

\section{Animals}

This study was conducted at the Henry Doorly Zoo, Omaha, NE between July 1991 and November 1994. On 20 occasions, adult (4-11 years of age), female tigers (six Panthera tigris altaica; four $P$. t. sumatrae and five generic Bengal $P$. $t$. tigris) were subjected to exogenous gonadotrophin (eCG/hCG) treatment and laparoscopy. Two Siberian and three Sumatran females were subjected to hormone treatment and laparoscopy on two occasions at least $I$ year apart. All remaining tigers were treated only once. Six females observed to be postovulatory at the time of laparoscopy were subjected to intrauterine AI (see below). On these occasions, two adult (5-9 years of age) males (one P. t. altaica; one P. t. sumatrae) served as sperm donors. Males were known to be fertile based on a history of siring living cubs. All tigers were housed separately, but were in olfactory and visual contact with conspecifics, and all were provided a carnivore diet (Nebraska Brand Feline Diet, North Platte, NE) daily.

\section{Induction of ovarian activity and laparoscopy}

Female tigers were administered gonadotrophins without regard to a specific stage of the reproductive cycle. Females received 1000 iu eCG (Equitech, Atlanta, GA) followed $80 \mathrm{~h}$ later by 750 iu hCG (Sigma Chemical Co., St Louis, MO) to stimulate follicular development and ovulation, respectively. Injections were delivered i.m. by syringe dart using a blow pipe apparatus.

Animals were fasted for at least $12 \mathrm{~h}$ before scheduled anaesthesia/laparoscopy. Females were anaesthetized at 39-42 h (Group I, $n=9$ ), 46-49 h (Group II, $n=5$ ) or $51-55 \mathrm{~h}$
(Group III, $n=5$ ) after hCG injection. Anaesthesia was induced with xylazine (i.m., Rompun, Mobay Corp., Shawnee, KS; $0.5 \mathrm{mg} \mathrm{kg}^{-1}$ ), diazepam (i.m., Valium ${ }^{(\mathrm{R})}$, Hoffman La Roche, Nutley, NJ; $0.1 \mathrm{mg} \mathrm{kg}^{-1}$ ) and ketamine $\mathrm{HCl}$ (i.m., Vetalar ${ }^{\mathrm{R})}$, Park-Davis, Detroit, MI; $5.0 \mathrm{mg} \mathrm{kg}^{-1}$ ). A surgical plane of anaesthesia was maintained by supplemental i.v. injections of ketamine $\mathrm{HCl}\left(1.5 \mathrm{mg} \mathrm{kg}^{-1}\right)$, given when necessary. Laparoscopy was performed as described by Phillips et al. (1982) and Donoghue et al. (1990). In brief, anaesthetized animals were placed in a supine position and tilted head-down at approximately $45^{\circ}$ from the vertical. A pneumoperitoneum was created with $\mathrm{CO}_{2}$ instilled through a transabdominally placed Verres needle. A $10 \mathrm{~mm}$ diameter, $180^{\circ}$ laparoscope (Richard Wolf Medical Instruments Corp., Rosemont, IL) was inserted through a $2 \mathrm{~cm}$ skin incision near the umbilicus and used to view the reproductive tract. All aspects of each ovary were examined for the number of preovulatory $(>2 \mathrm{~mm}$ in diameter, opaque or translucent) or ovulating ( $>2 \mathrm{~mm}$ in diameter, blood present at apex) follicles and corpora lutea (vascularized, luteinized structures raised above the ovarian surface) (Phillips et al., 1982).

\section{Semen collection and processing}

A prerequisite to $\mathrm{AI}$ attempts was consultation with the Tiger Species Survival Plan (SSP) Coordinator and Management Committee which operates under the auspices of the American Zoo and Aquarium Association (AZA). The Tiger SSP provided the recommendations for potential sperm donorrecipient pairings. The ejaculates used for insemination were collected using standardized anaesthesia and electroejaculation procedures reported by Wildt et al. (1987). After inducing anaesthesia with ketamine $\mathrm{HCl}$ (i.m., $5.0 \mathrm{mg} \mathrm{kg}^{-1}$ ), a rectal probe with three longitudinal electrodes and an $\mathrm{AC} 60 \mathrm{~Hz}$ sine-wave ejaculator were used to deliver 80 electrical stimuli of 3-7 volts over $20 \mathrm{~min}$. Semen was examined by phasecontrast microscopy for a subjective assessment of percentage sperm motility and progressive sperm motility (on a scale of $0-5$, where $0=$ no movement and $5=$ rapid forward progression; Howard et al., 1986). Aliquots were processed for determining the concentration of spermatozoa per $\mathrm{ml}$ of ejaculate and morphology (Howard et al., 1986). Immediately after collection, ejaculates were diluted with an equal volume of Ham's F10 medium containing 5\% fetal calf serum (Irvine Scientific, Santa Ana, CA). Diluted semen was centrifuged ( $300 \mathrm{~g}$ for $8 \mathrm{~min}$ ), the supernatant discarded, and the sperm pellet was resuspended into $500 \mu \mathrm{l}$ of fresh Ham's F10 medium. Processed samples were maintained at $5^{\circ} \mathrm{C}$ in darkness. Immediately before insemination, processed semen was assessed for percentage sperm motility, progressive motility and concentration. The number of motile cells inseminated depended upon the sperm concentration after processing. On one occasion, semen from a single male was divided and used to inseminate two females.

\section{Laparoscopic artificial insemination and pregnancy diagnosis}

Six females, determined to be postovulatory on the basis of definitive ovarian luteal activity, were artificially inseminated 
Table 1. Ovarian activity in tigers treated with eCG and hCG and anaesthetized at various times after hCG

\begin{tabular}{lcccc}
\hline & $\begin{array}{c}\text { Mean time } \\
\text { of anaesthesia } \\
\text { after hCG } \\
\text { Treatment } \\
\text { group }\end{array}$ & $\begin{array}{c}\text { Proportion } \\
\text { of females } \\
\text { ovulating }\end{array}$ & $\begin{array}{c}\text { Mean } \\
\text { number of } \\
\text { follicles }\end{array}$ & $\begin{array}{c}\text { Mean } \\
\text { number of } \\
\text { corpora lutea }\end{array}$ \\
\hline I & $41.1 \pm 0.8$ & $5 / 9$ & $12.8 \pm 2.2^{\mathrm{a}}$ & $1.3 \pm 0.6^{\mathrm{a}}$ \\
II & $47.4 \pm 0.8$ & $4 / 5$ & $5.0 \pm 1.7^{\mathrm{b}}$ & $7.0 \pm 1.8^{\mathrm{b}}$ \\
III & $55.2 \pm 0.7$ & $5 / 5$ & $5.8 \pm 2.1^{\mathrm{b}}$ & $8.6 \pm 1.1^{\mathrm{b}}$
\end{tabular}

${ }^{a, b}$ Within columns, values with different superscripts are significantly different $(P<0.05)$.

using a laparoscopic intrauterine procedure (Howard et al., 1992a, b; Donoghue et al., 1993). After examination of the ovaries as described above, a Palmer grasping forceps (Richard Wolf Medical Instruments Corp.) was inserted $3-5 \mathrm{~cm}$ lateral to the umbilicus and used to elevate each uterine horn to the ventral body wall. The uterine horn was cannulated using a sterile indwelling catheter (Critikon, Tampa, FL; 16 gauge, $57 \mathrm{~mm}$ long) which was inserted percutaneously into the proximal third of the uterine lumen. The catheter stylette was removed and replaced with sterile polyethylene tubing (PE-50, Intramedic, Clay Adams, Parsippany, NJ) containing $150 \mu \mathrm{l}$ of sperm suspension. The PE tubing was inserted beyond the tip of the catheter and into the uterine lumen, and the diluted spermatozoa were expelled into the lumen using about $0.4 \mathrm{ml}$ of air delivered from a standard $1 \mathrm{ml}$ plastic syringe. The entire procedure was repeated on the contralateral horn. Females were subjected to anaesthesia and ultrasound 45 days after AI to determine pregnancy status.

\section{Statistical analysis}

Values are means \pm SEM. Analysis of variance and the Fisher least significant difference procedure were used to test for significantly different effects of the number of follicles and corpora lutea observed in the treatment groups (SAS, 1987). Chi-squared analysis was used to compare the following results among treatment groups: (1) number of postovulatory females per total females; (2) total number of unovulated follicles per total number of ovarian structures (follicles plus corpora lutea); and (3) total number of ovulating follicles or corpora lutea per total ovarian structures.

\section{Results}

More preovulatory follicles $(P<0.05)$ were observed on the ovaries of females subjected to laparoscopy at the earliest interval after hCG compared with the other two time periods (more than a twofold difference, Table 1). Few corpora lutea were observed on ovaries of the five ovulating tigers in Group I; only one to two corpora lutea (mean, $1.3 \pm 0.6$ ) were observed per tiger. In contrast, the numbers of corpora lutea from Group II and III tigers averaged $7.8 \pm 0.8$ for the nine ovulating tigers (range, 5-13 corpora lutea per female) and only one of ten females failed to ovulate by the time of laparoscopy (Table 1).

Distinct differences in the morphology of follicles and corpora lutea were evident at laparoscopy. Two morphological types of follicles were observed: (1) preovulatory with no clear indications of impending ovulation (follicular surface smooth, clear with no evidence of luteinization or follicular haemorrhage); and (2) follicles in the process of ovulating (pre-corpora haemorrhagica). These latter follicles were opaque or translucent, often highly vascular with a bloody indentation in the follicular apex. Two types of corpora lutea were also evident: the corpora haemorrhagica or 'early' corpora lutea was less prominent than the fully mature corpora lutea, but with marked vascularization and haemorrhage within and surrounding the structure. By contrast, the mature corpora lutea was distinguished by greater height above the ovarian surface, distinct well-defined borders and vascularization without the bright red, bloody appearance of the early corpora lutea. If it is assumed that ovulating follicles and 'early' corpora lutea were indicative of impending or recently completed follicular rupture, then it could be concluded that most ovulations occurred by $46-49 \mathrm{~h}$ after hCG treatment. Group II tigers had the highest proportion of ovulating follicles and early corpora lutea (Table 2). In contrast, Group III females had fewest ovulatory follicles and early corpora lutea; the majority of ovarian structures were mature corpora lutea.

The four nonovulatory tigers in Group I were subjected to a second laparoscopy under the same anaesthesia regimen 32-41 days after the initial evaluation, to determine whether ovulation occurred after anaesthesia/laparoscopy. No corpora lutea were observed for three of the females evaluated, and one female had a single aged corpora lutea.

Of six post-ovulatory tigers inseminated with freshly ejaculated spermatozoa at the time of laparoscopy, one (anaesthetized $46 \mathrm{~h}$ after hCG; Group II) was diagnosed as pregnant by ultrasound 45 days after AI (Table 3). A healthy male cub was delivered naturally following a 111 day gestation.

There appeared to be little variation among Siberian and Sumatran tigers subjected to the same ovulation induction protocol (Fig. 1). The generic Bengal tigers were not evenly distributed across treatment groups, and, thus, were not statistically analysed. The numbers of follicles and corpora lutea were similar between subspecies at all treatment intervals with the exception of Group II, in which fewer ovarian follicles $(P<0.05)$ were observed in Sumatran compared with Siberian tigers (Fig. I).

\section{Discussion}

This study demonstrated that eCG and hCG induced ovarian follicular development and ovulation in tigers, but that ovulation success was tightly regulated by the timing of anaesthesia after administration of hCG. Furthermore, tigers anaesthetized before follicular rupture were mainly incapable of ovulating. In this context, tigers were remarkably similar to gonadotrophintreated domestic cats. When anaesthesia/laparoscopy is performed after the onset of ovulation, many more domestic cats ovulate, and the pregnancy rate is threefold higher than in cats 
Table 2. Status of follicular and luteal tissue on the ovaries of tigers treated with eCG and hCG and anaesthetized at various times after hCG

Parameter

Group I (39-42 h) Group II $(46-49$ h) Group II $(51-55$ h)

Number of follicles/total ovarian structures*

$105 / 111(94.6 \%)^{a}$

$6 / 111 \quad(5.4 \%)^{\mathrm{a}}$

$20 / 111(18.0 \%)^{\mathrm{a}}$

$0 / 111 \quad(0.0 \%)^{\mathrm{a}}$

$25 / 60(41.7 \%)^{b}$
$35 / 60(58.3 \%)^{b}$
$30 / 60(50.0 \%)^{b}$
$22 / 60(36.7 \%)^{b}$

$29 / 72(40.3 \%)^{\mathrm{b}}$

$4.3 / 72(59.7 \%)^{\mathrm{b}}$

$9 / 72(12.5 \%)^{\mathrm{a}}$

$37 / 72(51.4 \%)^{c}$

*Total ovarian structures equals the total number of follicles ( $>2 \mathrm{~mm}$ in diameter) plus total number of corpora lutea.

a.t. Within rows, values with different superscripts are significantly different $(P<0.05)$.

Table 3. Ovarian activity and inseminate traits at the time of artificial insemination (AI) of postovulatory tigers inseminated laparoscopically

\begin{tabular}{lcccccc}
\hline Female & $\begin{array}{c}\text { Interval from } \\
\text { hCG treatment } \\
\text { to } \mathrm{AI}(\mathrm{h})\end{array}$ & $\begin{array}{c}\text { Number of } \\
\text { follicles }\end{array}$ & $\begin{array}{c}\text { Number of } \\
\text { corpora lutea }\end{array}$ & $\begin{array}{c}\text { Sperm } \\
\text { motility }\end{array}$ & $\begin{array}{c}\text { Motile sperm } \\
\text { inseminated } \\
\left(\times 10^{6}\right)\end{array}$ & Pregnancy \\
\hline 1 & 46.0 & 6 & 8 & 85 & 16.3 & + \\
2 & 46.5 & 3 & 11 & 80 & 107.2 & - \\
3 & 49.3 & 0 & 8 & 50 & 13.3 & - \\
4 & 53.0 & 12 & 8 & 50 & 13.3 & - \\
5 & 55.0 & 9 & 5 & 75 & 160.5 & - \\
6 & 58.0 & 5 & 9 & 70 & 93.8 & - \\
\hline
\end{tabular}

that are preovulatory at the time of anaesthesia (Howard et al., 1992a). Thus, results confirm that ovulation in the Felidae appears particularly sensitive to anaesthesia, an event that can inhibit gonadotrophin-induced follicular rupture and corpora lutea formation. Although the mechanism by which anaesthesia prevents ovulation is unknown, Howard et al. (1992a) suggested a role for increased cortisol brought on by acute stress related to the manipulatory events associated with anaesthesia induction and/or laparoscopy. This theory is supported by studies demonstrating a depressed LH surge and inhibited ovulation after administration of adrenocorticotrophin releasing hormone to pigs in oestrus (Hennessy and Williamson, 1983). Kim et al. (1994) demonstrated lowered serum LH and a time-dependent block to ovulation when ether or pentobarbital was administered to rats. How ketamine $\mathrm{HCl}$ alters the ability of hCG to stimulate ovulation in tigers remains unknown, but warrants further investigation as this is usually the drug of choice for safely anaesthetizing this endangered species.

In addition, understanding how to overcome anaesthesiainduced ovulatory inhibition is important to developing successful AI protocols for felids. Data presented here on tigers and our earlier findings in domestic cats (Howard et al., 1992a) suggest that achieving conception after AI may be limited to only those attempts whereby spermatozoa are deposited after ovulation has commenced. Because the window of opportunity for successful AI is probably narrow and oocyte ageing and gamete asynchrony are of concern, it would be preferable to be able to inseminate immediately before (as well as immediately
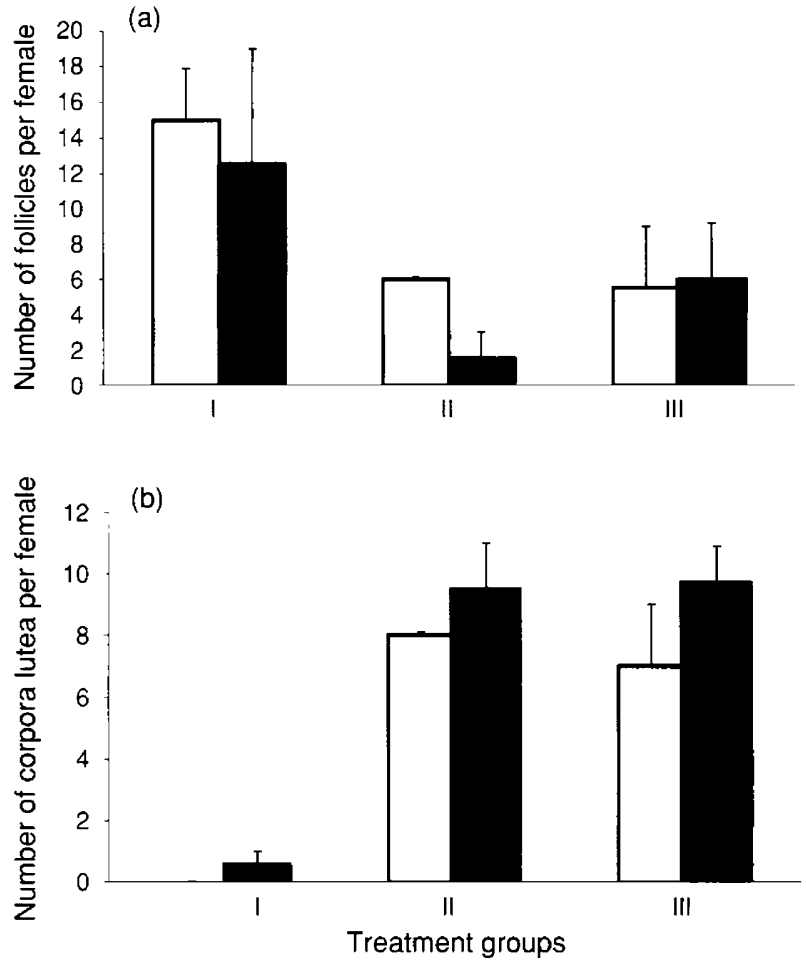

Fig. 1. Numbers of preovulatory follicles (a) and corpora lutea (b) in Siberian ( $\square$ ) and Sumatran ( $)$ ) tigers treated with the same eCG/hCG regimen and then examined by laparoscopy. 
after) expected ovulation. Thus, overcoming anaesthesiainduced inhibition is likely to increase overall AI success, particularly because it now is obvious that different felids ovulate at different times after gonadotrophin treatment. For example, most tigers in this study ovulated near $43-46 \mathrm{~h}$ after hCG administration. Some gonadotrophin-treated cheetahs (Wildt et al., 1981; Donoghue et al., 1992b) and pumas (Bonney et al., 1981; Miller et al., 1990) begin to ovulate as early as 24-26 h after hCG. However, Howard et al. (1992b) reported that none of three eCG/hCG-treated cheetahs had ovulated by $37-39 \mathrm{~h}$, but seven of seven ovulated $42.5-47.0 \mathrm{~h}$ after hCG. Barone et al. (1994) observed that most ovulations in pumas occur $4 \mathrm{I} \mathrm{h}$ after hCG administration. By contrast, domestic cats ovulate 25-30 h after hCG (Hamner et al., 1970; Sojka et al., 1970; Howard et al., 1992a). Therefore, it appears that ovulation in gonadotrophin-treated tigers occurs approximately $20 \mathrm{~h}$ later than in domestic cats. Finally, we contend that overcoming the inhibiting influence of anaesthesia may be a more efficient strategy than meticulously identifying the interval from hCG treatment to ovulation for each of the 36 species in the Felidae.

One of six postovulatory females inseminated became pregnant and produced a live cub. The relatively low efficiency of AI may have been related to a wide array of factors, including poor insemination timing after ovulation. Although anaesthesia performed too early inhibits ovulation, inseminating too late also will be detrimental owing to ageing of eggs. Of the six tigers, four were inseminated at least $49 \mathrm{~h}$ after hCG, suggesting that perhaps AI should have been conducted closer to $46 \mathrm{~h}$ after hCG.

Although the eCG/hCG treatment was effective in stimulating the formation of corpora lutea in Group II and III females, not all follicles ovulated by the time of laparoscopy. It was likely that these specific heterologous gonadotrophins resulted in secondary follicular growth or dysfunctional corpora lutea that perhaps perturbed temporal endocrine events, maybe only subtly but sufficiently to compromise fertilization, subsequent implantation or both processes. An abnormal oestradiol:progesterone ratio resulting in inadequate priming of the endometrium appears to be one reason for the high implantation failure rate in women after gonadotrophin therapy, IVF and embryo transfer (DeCherney et al., 1985). Because these mechanisms are poorly understood, some human IVF programmes provide supplemental progesterone during the early luteal phase of the IVF-ET cycle (DeCherney et al., 1985). Since residual follicles were present at the time of oviductal transfer of IVF tiger embryos, a recipient female that became pregnant was supported throughout gestation with progesterone implants (Donoghue et al., 1990). Thus, there may be some limited indirect evidence that eCG/hCG treatment in felids results in an abnormal endocrine milieu. The recent advent of noninvasive monitoring of endocrine pattern through the measurement of faecal steroid metabolites (validated for tigers by Brown et al., 1994) will be profoundly useful for determining the normalcy of endocrine profiles of gonadotrophin-treated felids.

Although the number of individuals from each subspecies was small, the data appeared to suggest that there were no distinct subspecies differences in response to exogenous gonadotrophins or onset of ovulation after hCG. This is important, in part, because it means that assisted reproduction techniques developed for one tiger subspecies will probably be applicable to others. Within the Felidae, this has not always been the case as there are distinct differences among felid species with respect to (1) eCG/hCG dose required to induce ovulation (Howard et al, 1992b, 1993) and (2) types of culture media required to promote and sustain sperm viability and provoke capacitation in vitro (Roth et al., 1994). In contrast, findings that exogenous gonadotrophin regimens have similar efficacy across these particular tiger subspecies may be related to recent findings of little subspecies differentiation in tigers using mitochondrial DNA analyses (J. Wentzel and S. O'Brien, personal communication).

Finally, the low pregnancy rate observed here in artificially inseminated tigers also may be related to naturally occurring fertilization failure and embryo mortality. An in depth study of in vivo embryogenesis in domestic cats reveals that about $30 \%$ of potential pregnancies fail between ovulation and implantation (Swanson et al., 1994). An improved understanding of factors influencing fertilization and embryo loss both after natural mating or assisted reproduction procedures will enhance our overall ability to produce sustainable pregnancies not only in domestic cats but also in wild felids.

The authors thank J. G. Howard, National Zoological Park for critical evaluation of methods, L. G. Simmons, N. M. Loskutoff and the veterinary and keeper staffs of the Omaha's Henry Doorly Zoo for dedicated and generous assistance. The authors also acknowledge R. L. Tilson and G. Brady, Coordinators of the Species Survival Plan for Siberian and Sumatran tigers for advice on recommended animal pairings. Financial support was provided by the Ralston Purina Big Cat Survival Fund and the Smithsonian Institution's Scholarly Studies Program.

\section{References}

Barone MA, Wildt DE, Byers AP, Roelke ME, Glass CM and Howard JG (1994) Gonadotrophin dose and timing of anaesthesia for laparoscopic artificial insemination in the puma (Felis concolor) Journal of Reproduction and Fertility 101 103-108

Bonney RC, Moore HDM and Jones DM (1981) Plasma concentrations of oestradiol-17 $\beta$ and progesterone and laparoscopic observations of the ovary in puma (Felis concolor) during oestrus, pseudopregnancy and pregnancy Journal of Reproduction and Fertility 63 523-531

Brown JL, Wasser SK, Wildt DE and Graham LH (1994) Comparative aspects of steroid hormone metabolism and ovarian activity in felids, measured noninvasively in feces Biology of Reproduction 51 776-786

DeCherney AH, Tarlatzis BC and Laufer N (1985) Follicular development: lessons learned from human in vitro fertilization American Journal of Obstetrics and Gynecology 153 911-923

Donoghue AM, Johnston LA, Seal US, Armstrong DL, Tilson RL, Wolf P, Petrini K, Simmons LG, Gross $\mathbf{T}$ and Wildt DE (1990) In vitro fertilization and embryo development in vitro and in vivo in the tiger (Panthera tigris) Biology of Reproduction 43 972-980

Donoghue AM, Johnston LA, Seal US, Armstrong DL, Simmons LG, Gross T, Tilson RL and Wildt DE (1992a) Ability of thawed tiger (Panthera tigris) spermatozoa to fertilize conspecific eggs and bind and penetrate domestic cat eggs in vitro Journal of Reproduction and Fertility 96 555-564

Donoghue AM, Howard JG, Byers AP, Goodrowe KL, Bush M, Blumer E, Lukas J, Stover J, Snodgrass K and Wildt DE (1992b) Correlation of sperm viability and gamete interaction and fertilization in vitro in the cheetah (Acinonyx jubatus) Biology of Reproduction 46 1047-1056

Donoghue AM, Johnston LA, Armstrong DL, Simmons LG and Wildt DE (1993) Birth of a Siberian tiger cub (Panthera tigris altaicia) following laparoscopic 
intrauterine artificial insemination Journal of $Z_{00}$ and Wildlife Medicine $\mathbf{2 4}$ $185-189$

Faulkner LC and Pineda MH (1980) Artificial insemination. In Veterinary Endocrinology and Reproduction, pp 330-366 Ed. LE McDonald. Lea and Febiger, Philadelphia

Hamner CE, Jennings J and Sojka NJ (1970) Cat (Felis catus) spermatozoa require capacitation Journal of Reproduction and Fertility 23 477-480

Hennessy DP and Williamson P (1983) The effects of stress and ACTH administration on hormone profiles, oestrus and ovulation in pigs Theriogenology 20 13-26

Howard JG, Bush M and Wildt DE (1986) Semen collection, analysis and cryopreservation in nondomestic mammals. In Current Therapy in Theriogenology, pp 1047-1053 Ed. DA Morrow. WB Saunders, Philadelphia Howard JG, Barone MA, Donoghue AM and Wildt DE (1992a) The effect of pre-ovulatory anaesthesia on ovulation in laparoscopically inseminated domestic cats Journal of Reproduction and Fertility 96 175-186

Howard JG, Donoghue AM, Barone MA, Goodrowe KL, Blumer E, Snodgrass K, Starnes D. Tucker M. Bush M and Wildt DE (1992b) Successful induction of ovarian activity and laparoscopic intrauterine artificial insemination in the cheetah (Acinonyx jubatus) journal of Zoo and Wildlife Medicine 23 288-300

Howard JG, Barone MA, Byers AP, Roth TL and Wildt DE (1993) Ovulation induction sensitivity and laparoscopic intrauterine insemination in the cheetah, puma and clouded leopard Journal of Andrology 1455

Howard JG, Byers AP, Brown JL, Schwartz RJ, Evans MZ, Barrett SJ and Wildt DE (1996) Successful ovulation induction and laparoscopic intrauterine artificial insemination in the clouded leopard (Neofelis nebulosa) Zoo Biology 15 $55-69$

Kim CY, Wakabayashi K and Nobunaga T (1994) Time-dependent ovulationblocking effect of ether anesthesia differs from pentobarbital in rats Tohoku Journal of Experimental Medicine 173 237-242

Miller AM, Roelke ME, Goodrowe KL, Howard JG and Wildt DE (1990) Oocyte recovery, maturation and fertilization in vitro in the puma (Felis concolor) Journal of Reproduction and Fertility 88 249-258
Moore HDM, Bonney RC and Jones DM (1981) Successful induced ovulation and artificial insemination in the puma (Felis concolor) Veterinary Record 108 282-283

Phillips LG, Simmons LG, Bush M, Howard JG and Wildt DE (1982) Gonadotropin regimen for inducing ovarian activity in captive wild felids Journal of American Veterinary Medical Association 181 1246-1250

Roth TL, Howard JG, Donoghue AM, Swanson WF and Wildt DE (1994) Function and culture requirements of snow leopard (Panthera uncia) spermatozoa in vitro Journal of Reproduction and Fertility 101 563-569

SAS Institute (1987) SAS User's Guide Version 5 Edition. SAS Institute, Inc. Cary

Sojka NJ, Jennings LL and Hamner CE (1970) Artificial insemination in the cat (Felis catus) Laboratory Animal Care 20 198-204

Swanson W, Roth TL and Wildt DE (1994) In vivo embryogenesis, embryo migration and embryonic mortality in the domestic cat Biology of Reproduction 51 452-464

Swanson W, Howard JG, Roth TL, Kaemmerer K, Alvarado T, Burton M, Starnes D, Sims L, Collins D and Wildt DE (1995) Laparoscopic intrauterine insemination in the ocelot (Felis pardalis) after ovarian stimulation with exogenous gonadotropins Theriogenology $\mathbf{4 3} 331$

Tilson RL, Foose T, Prince F and Traylor-Holzer K (1993) Tiger Global Survival Plan (GASP). IUCN/SSC Conservation Breeding Specialist Group, Apple Valley

Wildt DE, Platz CP, Seager SW] and Bush M (1981) Induction of ovarian activity in the cheetah (Acinonyx jubatus) Biology of Reproduction 24 217-222

Wildt DE, Phillips LG, Simmons LG, Goodrowe KL, Howard JG, Brown JL and Bush M (1987) Seminal-endocrine characteristics of the tiger and the potential for artificial breeding. In Tigers of the World: The Biology, Biopolitics, Management and Conservation of an Endangered Species, pp 255-279 Eds RL Tilson and US Seal. Noyes Publication, Park Ridge

Wildt DE, Monfort SL, Donoghue AM, Johnston LA and Howard JG (1992) Embryogenesis in conservation biology - or how to make an endangered species embryo Theriogenology 37 161-184 